\title{
Demographic profile and high risk factors in morbidly adherent placenta
}

\author{
Syed Masuma Rizvi, Farhana Fayaz*
}

Department of Obstetrics and Gynaecology, Government Medical College, Srinagar, Jammu and Kashmir, India

Received: 17 March 2016

Accepted: 12 April 2016

\section{*Correspondence:}

Dr. Farhana Fayaz,

E-mail: farhana.fayaz.10@gmail.com

Copyright: () the author(s), publisher and licensee Medip Academy. This is an open-access article distributed under the terms of the Creative Commons Attribution Non-Commercial License, which permits unrestricted non-commercial use, distribution, and reproduction in any medium, provided the original work is properly cited.

\section{ABSTRACT}

Background: Morbidly adherent placenta with its variants is one of the most feared complications causing high morbidity and mortality in obstetrics. The main objectives of the study were to evaluate the demographic profile and risk factors in morbidly adherent placenta.

Methods: A retrospective study was done in which case records of 40 patients diagnosed to have morbidly adherent placenta were reviewed. Demographic data including age, parity, gestational age and previous caesarean delivery or other uterine surgery, details of medical and obstetric history were recorded.

Results: A total of 24232 deliveries were conducted in the hospital. 40 patients were confirmed to have morbidly adherent placenta. The average age of the patients was 31.8 years and the mean parity was $1.80 .95 \%$ percent of the patients were booked in the study centre and only $5 \%$ percent were unbooked. $80 \%$ of the patients were from the rural area and $20 \%$ from the urban region. The average gestational age of the patient at diagnosis was 35.3 weeks and average gestational age at delivery was 36.2 weeks. The risk factors included previous caesarean section in 32 patients $(80 \%)$, with history of one C.S in 11 patients(27.5\%), with two C.S in 19 patients(47.5\%), and with history of three C.S in 4 patients (5\%). 8 patients $(20 \%)$ had history of both previous C.S and curettage and none had the history of curettage alone.

Conclusion: Morbidly adherent placenta is a potentially life threatening condition. Management of such patients requires early recognition of high risk women based on their clinical risk factors, with accurate preoperative diagnosis, good maternal counselling and planning of delivery.

Keywords: Placenta accreta, Caesarean section, Curettage

\section{INTRODUCTION}

Modern obstetrics has seen an increase in the lower segment caesarean section rate in recent times. A consequence of this rising rate is abnormal placentation in subsequent pregnancy, leading to clinical complications like placenta praevia and morbidly adherent placenta.

Placenta accreta was so rare before the 1970s, the reported incidence varied, but Breen and colleagues looked at the average reports from 1871 to 1972 and found it to be 1 in 7000 deliveries. ${ }^{1}$ Read and colleagues alarmingly reported an increasing rate of 1 in 4027 deliveries in 1970 s. $^{2}$ Maternal mortality with placenta accreta has been reported to be as high as $7 \%$ (AJOG 1996). ${ }^{3}$ This burden has actually worsened over the last few years as a result of rising trend of caesarean sections.

Derivation comes from a Latin word ac + crescere to grow from adhesion or coalescence or to adhere to. ${ }^{4}$ The occurrence of placenta accreta is linked to abnormal invasion at the placental implantation site due to defect within the decidua basalis and Nitabuch layer. Placenta accreta is a general term used to describe the clinical condition when part of the placenta, or the entire placenta, invades and is inseparable from the uterine wall, when the chorionic villi invade only the myometrium, the term placenta increta is appropriate; whereas placenta percreta describes invasion through the myometrium and 
serosa, and occasionally into adjacent organs, such as bladder. In clinical practice, these three variants are encountered in an approximate ratio of 80:15:5, respectively. ${ }^{5}$ In this document, the general term placenta accreta will refer to all 3 grades of abnormal placental attachment (placenta accreta, increta, and percreta) unless otherwise specified.

Morbidly adherent placenta is no longer a rare obstetric event; in fact it is now a common occurrence in a tertiary care set up. It is one of the most feared complication causing high morbidity and mortality in obstetrics.

The aim of this study is to evaluate the demographic profile and risk factors in patients with morbidly adherent placenta.

\section{METHODS}

This retrospective study was conducted for a period of one year (December 2015 to December 2016) in the department of obstetrics and gynaecology of the government medical college, Srinagar, which is the only tertiary obstetric care hospital in the Kashmir valley, where cases are referred to not only from peripheral hospitals and rural areas but also from local general practitioners.

Data of the patients with clinical and histological diagnosis was reviewed. Definition of placenta accreta was based on clinical and histological criteria using the presence of the following: (a) difficult manual or piecemeal removal of the placenta despite active management, (b) after removal of placenta heavy bleeding from implantation site, (c) Histologic confirmation of a hysterectomy specimen

The information collected was socio demographic data regarding age, residence, social status, education, income, antenatal registration and family history of the patient, obstetrical history regarding gravidity, parity, and gestational age at the time of diagnosis and at the time of delivery.

Details regarding the previous surgical procedures (if any) were collected. History of previous caesarean section, myomectomy, abortion, dilatation and curettage, or any other uterine surgery. Details regarding the history of smoking or any other substance abuse were noted down.

\section{RESULTS}

During the study period a total of 24232 deliveries were conducted in the hospital. Out of these 40 patients were confirmed to have morbidly adherent placenta. The average age of the patients was 31.8 years with 4 patients more than 35 years of age (table 1 ). The mean parity was 1.8 and none of the woman was primiparous (table 2). $95 \%$ percent of the patients were booked in the study centre and only $5 \%$ percent were unbooked. $80 \%$ of the patients were from the rural area and $20 \%$ from the urban region (table 3 ). The average gestational age of the patient at diagnosis was 35.3 weeks and average gestational age at delivery was 36.2 weeks (table 4).

Table 1: Age distribution of patients.

\begin{tabular}{|lll|}
\hline Age range & No of patients & Percentage \\
\hline $20-24$ & None & $0 \%$ \\
\hline $25-29$ & 10 & $25 \%$ \\
\hline $30-34$ & 26 & $65 \%$ \\
\hline$>35$ & 4 & $10 \%$ \\
\hline Total & 40 & $100 \%$ \\
\hline
\end{tabular}

Table 2: Parity of patients.

\begin{tabular}{|ll|l|}
\hline Parity & No of patients & Percentage \\
\hline 0 & 0 & $0 \%$ \\
\hline 1 & 14 & $35 \%$ \\
\hline 2 & 22 & $55 \%$ \\
\hline 3 & 4 & $10 \%$ \\
\hline$>4$ & 0 & $0 \%$ \\
\hline Total & 40 & $100 \%$ \\
\hline
\end{tabular}

Table 3: Demographic characteristics.

\begin{tabular}{|ll|l|}
\hline Characteristics & No. Of patients & Percentage \\
\hline Residence & \multicolumn{2}{|l|}{} \\
\hline Rural & 32 & $80 \%$ \\
\hline Urban & 8 & $20 \%$ \\
\hline Antenatal check up & & \\
\hline Booked & 38 & $95 \%$ \\
\hline Unbooked & 2 & $5 \%$ \\
\hline
\end{tabular}

Table 4: Gestational age at delivery.

\begin{tabular}{|lll|}
\hline Gestational age & No. Of patients & Percentage \\
\hline $28-31$ & 2 & $5 \%$ \\
\hline $32-35$ & 11 & $27.5 \%$ \\
\hline$>36$ & 27 & $67.5 \%$ \\
\hline
\end{tabular}

Table 5: Risk factors.

\begin{tabular}{|ll|}
\hline Risk Factors & Percentage \\
\hline Previous one C.S & $27.5 \%$ \\
\hline Previous two C.S & $47.5 \%$ \\
\hline Previous three C.S & $5 \%$ \\
\hline Previous C.S and curettage & $20 \%$ \\
\hline Only curettage & $0 \%$ \\
\hline No risk factors & $0 \%$ \\
\hline
\end{tabular}

The risk factors included previous caesarean section in 32 patients $(80 \%)$, with history of one C.S in 11 patients(27.5\%), with two C.S in 19 patients(47.5\%), and with history of three C.S in 4 patients $(5 \%) .8$ patients (20\%) had history of both previous C.S of the patients and none had the history of curettage alone (table 5). 


\section{DISCUSSION}

The incidence of morbidly adherent placenta in this study was $0.165 \%$. This is higher than the incidence found by Wadhwa L et al $(0.048 \%)^{6}, 0.046 \%$ by Sofiah $\mathrm{S}$ et $\mathrm{al}^{7}$, $0.04 \%$ by Aggarwal R et al. ${ }^{8}$ This incidence is lower than the incidence found in the study conducted by Eshkoli $\mathrm{T}$ et al $(0.4 \%)^{9}$, and Nighat sultana et al $(0.35 \%){ }^{10}$ According to the American college of Obstetrics and Gynecology the incidence of placenta accreta was 1:2500 per delivery. ${ }^{11}$ Population based studies have suggested that the incidence of placenta accreta has increased over the last three decades, and occurs in 1 in 533 deliveries (AJOG 2005). ${ }^{12}$

The mean age of the patients with morbidly adherent placenta was 31.8 years and mean parity was 1.8 . This was comparable with the study done by Aggarwal R et al with mean age $(27.7 \pm 4.2)$ and mean parity $(2.5 \pm 0.9) .{ }^{8} \mathrm{It}$ was lower than the results found in study conducted by Sofiah $\mathrm{S}$ et al (mean age 35 years and parity 4.5$)^{7}$, Sultana $\mathrm{N}$ et al (mean age 33.3 and parity 4$)^{10}$, Ara A et al (mean age 33.8 and parity 3$)^{13}$.

In our study history of previous caesarean section (80\%) and history of dilatation and curettage were the two most important risk factors for morbidly adherent placenta. $47.5 \%$ had history of two caesarean sections, $27.5 \%$ with history of one caesarean section. $20 \%$ of the patients had history of previous section and curettage both.

Thus, women at greatest risk of placenta accreta are those who have myometrial damage caused by a previous caesarean delivery with either anterior or posterior placenta praevia overlying the uterine scar. Increasing numbers of previous caesarean section magnify this risk with an eight fold increase in incidence of placenta accreta after two or more caesarean section. ${ }^{14}$ In presence of placenta praevia the risk of placenta accreta is $3 \%$, $11 \%, 40 \%, 61 \%$ and $67 \%$ for the first, second, third, fourth and fifth or greater repeat caesarean deliveries. ${ }^{15}$ Placenta praevia without previous uterine surgery is associated with a $1-5 \%$ of placenta accreta. Besides advanced maternal age and multiparity, reported risk factors include any condition resulting in myometrial tissue damage followed by secondary collagen repair, such as previous myomectomy, endometrial defects due to vigorous curettage ${ }^{16}$, thermal ablation ${ }^{17}$ and uterine artery embolization $^{18}$.

\section{CONCLUSIONS}

The incidence of placenta accreta has increased dramatically over the last three decades, in concert with the increase in caesarean delivery rate. It occurs when there is a defect in decidua basalis, resulting in abnormally invasive placentation of the placenta. In addition to caesarean section, prior curettage, uterine surgery and myomectomy have all been associated with abnormal placentation. The maternal mortality risk may reach $7 \%^{3}$ due to the surgery related complications. In our low resource setting, due to illiteracy and failure to recognize the need for antenatal care, many patients with these serious obstetric disorders are either not antenatally booked, or booked at small clinics or maternity homes, where either they are not diagnosed antenatally, or diagnosis is delayed till they suffer serious haemorrhage. As a result, when these patients are referred to tertiary care hospitals, they have already suffered a major blood loss leading to hemodynamic instability. Management of patients with placenta accreta therefore requires early recognition of high risk women based on their clinical risk factors, with accurate preoperative diagnosis, good maternal counselling and planning of delivery.

\section{Funding: No funding sources}

Conflict of interest: None declared

Ethical approval: The study was approved by the Institutional Ethics Committee

\section{REFERENCES}

1. Breen JL, Neubecker R, Gregori CA, Franklin JE Jr. Placenta accreta, increta, percreta: survey of 40 cases. Obstet gynecol. 1977;49:43-7.

2. Read JA, Cotton DB, Miller FC. Placenta accreta: changing clinical aspects and outcome. Obstet Gynecol. 1980;56(1):31-4.

3. Brien JM, Barton JR, Donaldson ES. The management of placenta percreta: conservative and operative strategies. Am J Obstet Gynecol. 1996;175:1632-7.

4. Benirschke K, Burton, Baergen RN: Pathology of the Human Placenta, 6th Ed. New York, Springer. 2012;204.

5. Wong, HS, Cheung. YK, Zuccollo, J et al, Evaluation of sonographic diagnostic criteria for placenta accreta; J Clin Ultrasound. 2008;36(9):551.

6. Wadhwa L, Gupta S, Gupta P, Satija B, Khanna R. ESI-PGIMR, Basaidarapur, Delhi Open Journal of Obstetrics and Gynecology, 2013, 3, 217-21.

7. Sofiah S, MMed, Late Fung YC, FRCOG. Department of $\mathrm{O} \& \mathrm{G}$, medical faculty, university Malaya, 59100 Kuala Lumpur, fetal medicine specialist, mater mothers hospital, Brisbane Med J. 2009;64(4).

8. Aggarwal R, Suneja A, Vaid NB, Yadav P, Sharma A, Mishra K. The Journal of Obstetrics and Gynecology of India. 2012;62(1):57-61.

9. Eshkoli T, Weintraub AY, Sergienko R, Sheiner E. Am J Obstet Gynecol. 2013;208:219.e1-7.

10. Sultana N, Mohyuddin S, Jabbar T. Department of obstetrics and gynaecology, combined military hospital Rawalpindi. J Ayub Med Coll Abbottabad. 2011;23(2).

11. ACOG committee opinion. Placenta accreta. American College of Obstetricians and gynecologists. INT J Gynaecol Obstet. 2002;202;77:77-8. 
12. Wu S, Kocherginsky M, HIibbard JU. Abnormal placentation 20 year analysis. Am J Obstet Gynecol 2005:192:1458-61.

13. Hasan AA, Hasan JA, Khan AA. Hamdard University Hospital and Two Private Hospitals, Journal of Surgery Pakistan. 2009;14(4).

14. Wu S, Kocherginsky M, Hibbard JU. Abnormal placentation: twenty year analysis. Am J Obstet Gynecol. 2005;192:1458-61.

15. Silver RM, Landon MB, Rouse DJ, Leveno KJ, Spong CY, Thom EA, et al. Maternal morbidity associated with multiple repeat cesarean deliveries. Obstet Gynecol. 2006;107:1226-32.
16. Al-Serehia, Mhoyan A, Brown M, Bernichke K, Hull A, Pretorius DH. Placenta accreta: an association with fibroids and asherman syndrome. J Ultrasound med. 2008;27;1623-8.

17. Hamar BD, Wolf EF, Koddmann PH, MarcoviciI. Premature rupture of membranes. Placenta increta and hysterectomy in a pregnancy following endometrial ablation. J Perinatol. 2006;26;135-7.

18. Pron G, Rski MF, Benet J, Vilos G, Common A, Vanderburghl. Pregnancy after uterine artery embolization for leiomyomata: the Ontario multicenter trial. Obstet Gynecol. 2005;105:67-76.

Cite this article as: Rizvi SM, Fayaz F. Demographic profile and high risk factors in morbidly adherent placenta. Int $\mathrm{J}$ Reprod Contracept Obstet Gynecol 2016;5:1617-20. 